
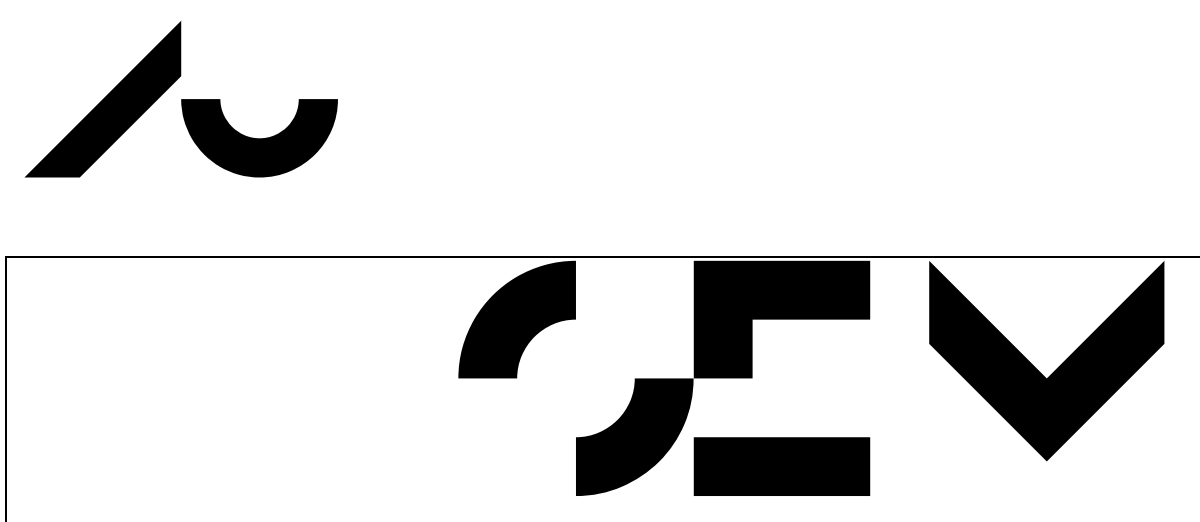

Economics Working Paper

2010-13

\title{
Worker and Firm Heterogeneity in Wage Growth: An AKM approach
}

Kenneth L. Sørensen and Rune M. Vejlin

School of Economics and Management

Aarhus University

Bartholins Allé 10, Building 1322

DK-8000 Aarhus C - Denmark

Phone +4589421610

Mail: oekonomi@econ.au.dk

Web: www.econ.au.dk 


\title{
Worker and Firm Heterogeneity in Wage Growth: An AKM approach*
}

\author{
Kenneth L. Sørensen ${ }^{\dagger}$ and Rune M. Vejlin ${ }^{\dagger}$ \\ Aarhus University and $L M D G$
}

August 10, 2010

\begin{abstract}
This paper estimates a wage growth equation containing human capital variables known from the traditional Mincerian wage equation with year, worker and firm fixed effects included as well. The paper thus contributes further to the large empirical literature on unobserved heterogeneity following the work of Abowd, Kramarz, and Margolis (1999). Our main contribution is to extend the analysis from wage levels to wage growth. The specification enables us to estimate the individual specific and firm specific fixed effects and their degree of explanation on wage growth. The analysis is conducted using Danish longitudinal matched employer-employee data from 1980 to 2006. We find that the worker fixed effect dominates both the firm fixed effect and the effect of the observed covariates. Worker effects are estimated to explain seven to twelve per cent of the variance in wage growth while firm effects are estimated to explain four to ten per cent. We furthermore find a negative correlation between the worker and firm effects, as do nearly all authors examining wage level equations.
\end{abstract}

Keywords: MEE data, fixed effects, wage growth.

JEL codes: J21, J31

${ }^{*}$ We thank Michael Svarer, Henning Bunzel and participants at the European Society for Population Economics Conference in Essen, Germany (June 2010) for comments and LMDG for providing the data. Vejlin greatly acknowledge financial support from the Danish Social Sciences Research Council (grant no. FSE 09-066745).

${ }^{\dagger}$ School of Economics and Management, Aarhus University, Building 1322, Bartholins All 10, DK-8000 Aarhus C, Denmark. Correspondence to; Kenneth Lykke Sørensen, email: ksoerensen@econ.au.dk. 


\section{Introduction}

A well known fact about the labor market is that there exists a large degree of wage dispersion in the levels of wages. The same fact can be said about wage growth, but this has not yet been exploited to its full extent. Wage growth and wage levels are of course closely connected as wage growth is the first difference of wage levels, but the explanation of wage growth is different from the explanation of wage levels. Typically, observable characteristics are estimated to explain around 30 per cent of the variation in wage levels while they are able to explain much less of the variation in wage growth. ${ }^{1}$ This leads to other differences in the explanation given by the unobserved effects as well, and it is especially interesting that Abowd, Kramarz, and Margolis (1999) (henceforth denoted AKM), who introduced how to statistically analyze simultaneous observed and unobserved individual- and firmlevel heterogeneity, show that when controlling for unobserved heterogeneity they can explain nearly all of the variation of wages.

The methods have ever since been broadly explored by authors like Abowd and Kramarz (1999), Abowd, Finer, and Kramarz (1999) (American data), Abowd, Creecy, and Kramarz (2002) (American and French data), Barth and Dale-Olsen (2003) (Norwegian data), Gruetter and Lalive (2004) (Austrian data), Andrews, Gill, Schank, and Upward (2008) (German data), and Sørensen and Vejlin (2009) (Danish data). Often, the main focus has been on the question of whether high wage workers are sorting into high wage firms. ${ }^{2}$ Almost all studies done to date find small negative or zero sorting in wages. AKM show that the worker effect strongly dominates the firm effects in explaining the wage determination. The worker effect together with the correlation between the worker and the firm effects have been given most attention in the literature. In the literature following AKM the common approach so far has been to focus on the wage level, while very little effort has been spent on explaining the wage growth distribution using these methods. The levels of wages have been the natural starting point of research for several reasons. Firstly, wage levels have been the natural dependent variable in any human capital wage equation ever since Mincer (1958) developed the so-called Mincerian wage equation. Secondly, much earlier research has been forced to use annual wage income making a credible wage growth practically difficult to calculate as the direct wages will be troublesome to extract

\footnotetext{
${ }^{1}$ See e.g. Abowd, Kramarz, and Margolis (1999, Table II), Barth and Dale-Olsen (2003, Table 2) and Mortensen (2005) for analysis of wage level equations. In section 5 Robustness we find a degree of explanation of 2.24 per cent in an OLS regression on wage growth.

${ }^{2} \mathrm{~A}$ high wage worker is in the terminology by AKM a worker receiving above what he is expected to, given his level of observable characteristics. A high wage firm is a firm paying wages higher than expected given these same characteristics.
} 
and compare with the corresponding wage one year before, since it might be contaminated by different hours worked and changing bonus schemes, thus containing lots of measurement error.

The goal of this paper is to estimate an empirical model of wage growth allowing for both worker and firm fixed effects. We show that much less of the variation of wage growth can be explained by observables, worker and firm effects compared to the degree of explanation in the levels of wages. The common results that unobserved worker heterogeneity is more important than unobserved firm heterogeneity and observable covariates are found to be the case for the variance in wage growth as well. Furthermore, we find a negative correlation between the estimated worker specific effects and the estimated firm specific effects of a much stronger magnitude than typically found in wage level analysis.

A more theoretical literature inspired by the empirical findings of AKM argues that the fixed effects in the wage equation do not necessarily correlate very well with the underlying productivity of the firm and worker, respectively. When motivating the AKM specification as a structural representation of the wage equation, it is generally assumed that the outside options of workers and firms are independent of the prevailing match. Recently, several studies have illustrated the implications of relaxing this assumption. Eeckhout and Kircher (2009) and Lopes de Melo (2008) both generate a non-monotonicity in the wage equation due to high productivity firms facing better outside options than their counterparts when they match with a low productivity worker. A low productivity worker has to compensate a high productivity firm for giving up the opportunity to match with a more productive worker. Eeckhout and Kircher (2009) illustrate the insufficiency of wage data alone to identify sorting in the labor market: for every production function that induces positive sorting they can find a production function inducing negative sorting whilst generating identical wages. In Postel-Vinay and Robin (2002) the dynamic nature of the wage bargaining process implies that although workers always move up in the productivity distribution upon a job-to-job transition, a move may be associated with a drop in wages. Bagger and Lentz (2008) adopt this wage setting in an on-the-job search model with endogenous search effort and show that positive sorting can be consistent with a negative correlation between the fixed effects in the wage equation. Shimer (2005) makes the same point within an assignment model. This recent strand of the literature shows that one should be very careful when interpreting AKM type wage decompositions and, hence, we do not push our results in the direction of revealing the underlying productivity structure of the labor market.

Given the theoretical interest alluded to above, one of the contributions of this paper is also to 
investigate whether or not the structural models need to take into account that the growth rate of wages can be different for different workers. An implication of the human capital model by Mincer (1974) is parallel log earnings profiles across schooling levels. Heckman, Lochner, and Todd (2003) test whether data supports this parallel implication and find that only 1940s and 1950s US Census data support parallel log earnings profiles across schooling levels, while formal econometric tests rejects any support for such parallelism for newer data (1960 to 1990). Connolly and Gottschalk (2006) show that log earnings profiles are not even parallel when controlling for workers making job-to-job transitions and workers experiencing a non-employment spell between jobs with high educated workers experiencing higher wage growth than lower educated workers.

Postel-Vinay and Robin (2002) and Bagger, Fontaine, Postel-Vinay, and Robin (2007) produce wage equations in which the wage change does not depend on the worker, but only on the current and the last firm that the worker was in. E.g., if it is a high productivity firm then wage changes are large, since the initial wage is low, because the worker is willing to accept an initial low wage at a high productivity firm in order to get higher wage raises in the future, and then high wage firm matches all wage offers.

The paper is organized as follows: Section 2 presents our empirical model, discusses identification and summarizes the implementation procedure. We describe the Danish IDA data in Section 3 and, in particular, the realized mobility patterns that are of high importance for both identification and precision of the parameters. In Section 4 we present the results of the wage decomposition and the analysis taking the estimated parameters as input. In section 5 we analyze the robustness of our model. Section 6 concludes.

\section{The Two-Way Fixed Effects Model}

We will be using a wage specification inspired by Abowd, Kramarz, and Margolis (1999) and Abowd, Creecy, and Kramarz (2002) with wage growth decomposed into a linear relationship between observed covariates, an unobserved worker fixed effect, an unobserved firm fixed effect and an error term.

Let $i \in \mathcal{I}=\{1, \ldots, I\}$ index workers and let worker $i$ be represented by $N_{i}$ observations indexed by $n \in \mathcal{N}_{i}=\left\{1, \ldots, N_{i}\right\}$ totaling $N^{*}=\sum_{i \in \mathcal{I}} N_{i}$ observations in the data. The set of firms is $\mathcal{J}=\{1, \ldots, J\}$. We assume that worker $i$ 's log wage growth from time $t-1$ to time $t$ when employed 
at firm $J(i, t)$ arises from the linear model given by ${ }^{3}$

$$
\Delta w_{i t}=x_{i t}^{\prime} \beta+\theta_{i}+\psi_{J(i, t)}+\varepsilon_{i t},
$$

where $\Delta w_{i t}=w_{i t}-w_{i t-1}, x_{i t}$ is a $1 \times K$ vector of observed time-varying covariates, $\beta$ is a conformable vector of slope parameters, $\theta_{i}$ and $\psi_{J(i, t)}$ are worker specific and firm specific components of the variation of log wage growth, respectively. $\varepsilon_{i t}$ is the residual wage growth. Our specification is different from the original AKM specification as the error structure allows for time varying unobservables to have long term consequences on wage growth. Kramarz, Machin, and Ouazad (2009) have a specification much like ours. They analyze a value added model in which they decompose the progress of children in the English primary education system into a child fixed effect (corresponding to our worker effect), a school-grade-year effect (corresponding to our firm effect) and an error term. A crucial difference between our analysis and the one by Kramarz, Machin and Oazad is that we have up to 26 time periods per person while they analyze the change in test scores for English primary school pupils over two periods; period one at age $6 / 7$ and period two at age $10 / 11$.

We shall treat the residual $\varepsilon_{i t}$ in (1) as a genuine statistical residual. We thus impose the identifying assumptions

$$
\begin{aligned}
& E\left[\varepsilon_{i t} \mid x_{i t}, i, t, J(i, t)\right]=0, \quad \forall n \in \mathcal{N}_{i} \quad \text { and } \quad \forall i \in \mathcal{I} \\
& \operatorname{Cov}\left[\varepsilon_{i t}, \varepsilon_{h s} \mid x_{i t}, x_{h s}, i, h, t, s, J(i, t), J(h, s)\right]= \begin{cases}\sigma^{2}<\infty & \forall i=h, t=s \\
0 & \text { otherwise. }\end{cases}
\end{aligned}
$$

Equation (2) ensures strict exogeneity, i.e. it rules out endogenous mobility.

\subsection{Identification of the Person and Firm Fixed Effects}

We need to make sure that both person and firm effects are identified. This is no trivial problem though, since the usual techniques by sweeping out the singular row and column combinations from the normal equations of the system cannot be done as the normal equations are solved without actually computing the generalized inverse. Instead, person and firm effects can be identified by forming groups of connected workers and firms using the grouping algorithm developed by Abowd, Creecy, and Kramarz (2002). To do this, one must use the movers to tie workers and firms together

\footnotetext{
${ }^{3}$ Note that for the comparison regressions of wages in levels, we use the same specification, but with wage levels as left hand side variables instead of wage growth.
} 
such that each group consists of all the workers who have ever worked for any of the firms within the group and all the firms at which any of the workers has ever been employed at. ${ }^{4}$ This implies that a group is a connection of workers and firms in a graph theoretical sense. The algorithm results are displayed in table 1.

As none of the firms in group $k$ is connected to any of the firms in group $h$ for all $k \neq h$ we cannot compare firm and worker effects between groups. This leaves us with the option of performing the analysis on each group separately or focusing on one group only within which worker and firm specific effects can be identified using conventional methods from analysis of covariance. Table 1 shows that after doing the graph theoretical grouping algorithm by Abowd, Creecy, and Kramarz (2002) the largest group contains almost all observations (99 per cent), workers (98 per cent) and firms (91 per cent) so we will focus on the largest group only and discard all observations belonging to any other group than the largest. This is also the normal procedure in the literature.

It is useful to write equation (1) in matrix notation;

$$
\mathbf{w}=\mathbf{Z} \beta+\mathbf{D} \theta+\mathbf{F} \psi+\epsilon,
$$

where $\mathbf{w}$ and $\epsilon$ are $N^{*} \times 1$ vectors, $\mathbf{D}$ is an $N^{*} \times N$ matrix of worker dummy variables, $\mathbf{F}$ is an $N^{*} \times J$ matrix of firm dummy variables and $\mathbf{Z}$ is $N^{*} \times K$ matrix of covariates. $\theta$ is an $N \times 1$ parameter vector, $\psi$ is a $J \times 1$ parameter vector and $\beta$ is a $K \times 1$ parameter vector. $^{5}$

Equation (4) is known as the Least Squares Dummy Variable method (LSDV), which is a twoway high dimensional fixed effects model. There are several ways to estimate such a model. AKM note that the LSDV estimation of (4) requires the estimation of $N$ worker effects and $J$ firm effects. Since $N$ is often in millions and $J$ is often in thousands, such an estimation is unfeasible with standard approaches. We use the conjugate gradient (CG) algorithm also used by Abowd, Creecy, and Kramarz (2002) and Kramarz, Machin, and Ouazad (2009) to solve the problem. The CG algorithm deals with the high dimensionality of the data by using sparse matrices and iterates the solution according to a convergence criteria which we have set to $10^{-14}$.

\footnotetext{
${ }^{4}$ See ACK for a more detailed description of the grouping algorithm.

${ }^{5}$ Note that (4) is actually a generalization of the model used by Abowd, Kramarz, and Margolis (1999). Instead of using wages in level we use wage growth and have furthermore assumed that the firm effects are all constant over time, hence $m=1$ in AKM's model.
} 


\section{The Data}

The data source used in this paper is the Integrated Database for Labor Market Research (IDA) kept by Statistics Denmark (SD). The data are confidential but our access is not exclusive. IDA is a matched employer-employee longitudinal database containing socio-economic information on the entire Danish population, the population's attachment to the labor market, and at which firms the worker is employed. Both persons and firms can be monitored from 1980 onwards. The reference period in IDA is given as follows; The linkage of persons and firms refers to the end of November, ensuring that seasonal changes (such as e.g. shutdown of establishments around Christmas) do not affect the registration, meaning that the creation of jobs in the individual firms refers to the end of November. On the other hand, the background information on individuals mainly refers to the end of the year. ${ }^{6}$ Our gross sample contains all workers having their main employment at a private firm in the period of $1980-2006 .^{7}$

\subsection{The Sample}

The raw data consists of $60,847,593$ yearly wage observations. The data is then narrowed down to the sample of estimation by the following corrections according to table 2 .

First, since we divide the sample into educational groups, the observations with missing educational information are deleted (1,256,538 observations deleted). Second, we only include observations after the completion of the highest education $(11,064,910$ observations deleted). I.e. if a worker has a job with some lower education and then achieves a new (mainly higher) education, we only include the observations belonging to his last education and are thus deleting all observations prior to the completion of his highest education. This is done such that we are ensured not to compare e.g. an economist when working as an economist with when he was working as a clerk in a department store before finishing his studies. The private and public sector labor markets are very different, and we will only be looking at the private sector, thus deleting all public sector observations $(18,207,737$ observations deleted). Furthermore, if a worker is currently undertaking education he is deleted as well (938,862 observations deleted). If the experience measure of a worker is negative or above his age less his years of education the observation is deleted (15,168 observations deleted). All non-full-time employment observations are deleted $(2,402,026$ observations) and so are observations with negative

\footnotetext{
${ }^{6}$ See a more detailed documentation on IDA constructed by SD: http://www.dst.dk/HomeUK/Guide/documentation/Varedeklarationer/emnegruppe/emne.aspx?sysrid=1013

${ }^{7}$ Since we will be using the first difference of wages the estimation period will be $1981-2006$.
} 
or non-credible hourly wages $\left(65,571+1,115,560\right.$ observations deleted). ${ }^{8}$ To deal with outliers, we delete all observations with wages in the top and bottom percentile of the wage distribution $(248,899$ $+254,555$ observations), and finally, as we use wage growth, we have deleted all the observations in which we observe a worker for the first time (4,395,944 observations). ${ }^{9}$ Totaling a sample of $20,836,823$ observations which then is divided into three educational groups, which are low, medium and high for both men and women. These groups are thoroughly described in the next section.

\subsection{Observable Characteristics}

The IDA data contains actual labor market experience but only measured from 1964 and onwards. Hence, for workers entering the labor market prior to 1964 this experience measure is left-censored. Therefore, we construct our own measure of experience as potential experience (age less the total length of education less schooling starting age) at the first observation for a given worker and then add actual increments in experience. Woodcock (2008) uses a similar measure except that he only knows whether or not a worker was employed sometime during a quarter, whereas we have more precise information on actual experience accumulated during each year. Sørensen and Vejlin (2009) also use this measure. Table 3 presents summary statistics of our measure of experience. In our sample men are relatively more experienced than women and low educated are more experienced than high educated. The latter partly reflects that high educated enter the labor market later.

The time varying observables, $x_{i t}^{\prime}$, consist of calendar time and labor market experience. ${ }^{10}$ In the implementation we include a full set of year dummies and parameterize the experience profile by including experience and experience squared. Time-invariant characteristics are gender and length of education. We construct an education measure which divides the sample into three mutually exclusive groups: less than 12 years of education, 12-14 years and more than 14 years. The first group contains high-school drop-outs, the second contains high-school graduates, individuals with a vocational education, and individuals with a short cycle tertiary education, and the third contains those with medium and long cycle tertiary educations. We will denote these educational groups as low, medium and high educated workers, respectively. The IDA data does contain considerable

\footnotetext{
${ }^{8}$ The hourly wage measure is calculated on the basis of payments to the Danish mandatory pension scheme, ATP which is a step-function of hours worked. If Statistics Denmark report this hourly measure as non-credible, we delete the associated observation.

${ }^{9}$ But only after calculating the wage growth.

${ }^{10}$ In the robustness section we include dummies for marital status, parenthood and size of the firm current and one period before to check whether year dummies and experience profiles fully capture observable heterogeneity.
} 
further information on workers. However, this paper focuses on disentangling worker and firm effects and not on which particular characteristics on either the worker or firm side that drive wage growth differentials. Hence, the time-invariant worker characteristics included in the analysis are chosen such that well-defined subsamples can be formed on which separate analysis can be performed.

Since the firm effect in the AKM model is identified from workers moving between different firms it is important to have long panels and a lot of job changes per worker. Table 4 shows the distribution of number of observations for each worker. Each worker appears in the sample on average 9.85 times with men being on average more frequently than women. We have more than ten observations for almost 40 per cent of the entire sample divided on 44 per cent of the male sample and 31 per cent of the female sample. It is only 18 per cent of the total number of workers that appears less than three times in our total sample.

Table 5 reports the distribution of number of employers per worker. Approximately two thirds of all workers are in multiple firms and 40 per cent of the workers in the entire sample have three or more different employers. On average, each worker has 2.52 different employers. 45 percent of all men and 32 per cent of all women have three or more employers. To compare these figures, Abowd, Kramarz, and Margolis (1999) have a maximum of ten years of observations, but only 10 per cent of their workers are observed ten times and only one half of the workers in their sample changes employers, i.e. we have more observations per worker and more frequent job changes in our sample compared to the original sample used to estimate the AKM model.

The main interest in this paper is to estimate the effect of firm and worker heterogeneity on wage growth. Figure 1 shows the cross-section distribution of wage growth over all years. The wage growth distribution is almost symmetrical around a mean value of three per cent and there are considerable variations.

\section{The Results}

In this section we present results for model (4). The model is estimated both in terms of wage growth and wage levels, i.e. the original AKM model. This is done in order to compare the two models. Model (4) is also estimated on subgroups, which allow for the firm effect, the year effect and the experience profile to differ between subgroups. 


\subsection{Contributions of Fixed Effects to the Variance of Wage Growth}

Notice that the variance of either wage growth or levels can be decomposed into pairwise covariances between the dependent variable and independent variables. This is shown in equation (5) by inserting for the wage growth equation;

$$
\begin{aligned}
\operatorname{Var}\left(\Delta w_{i t}\right) & =\operatorname{Cov}\left(\Delta w_{i t}, \Delta w_{i t}\right)=\operatorname{Cov}\left(\Delta w_{i t}, x_{i t}^{\prime} \hat{\beta}+\hat{\theta}_{i}+\hat{\psi}_{J(i, t)}+\hat{\varepsilon}_{i t}\right) \\
& =\operatorname{Cov}\left(\Delta w_{i t}, x_{i t}^{\prime} \hat{\beta}\right)+\operatorname{Cov}\left(\Delta w_{i t}, \hat{\theta}_{i}\right)+\operatorname{Cov}\left(\Delta w_{i t}, \hat{\psi}_{J(i, t)}\right)+\operatorname{Cov}\left(\Delta w_{i t}, \hat{\varepsilon}_{i t}\right)
\end{aligned}
$$

Dividing through by the variance of the dependent variable lets us interpret each component as the relative contribution to the explanation of the variance of the dependent variable. I.e. the degree of explanation by each component arising from the decomposition is given by: ${ }^{11}$

$$
\frac{\operatorname{Cov}\left(\Delta w_{i t}, x_{i t}^{\prime} \hat{\beta}\right)}{\operatorname{Var}\left(\Delta w_{i t}\right)}+\frac{\operatorname{Cov}\left(\Delta w_{i t}, \hat{\theta}_{i}\right)}{\operatorname{Var}\left(\Delta w_{i t}\right)}+\frac{\operatorname{Cov}\left(\Delta w_{i t}, \hat{\psi}_{J(i, t)}\right)}{\operatorname{Var}\left(\Delta w_{i t}\right)}+\frac{\operatorname{Cov}\left(\Delta w_{i t}, \hat{\varepsilon}_{i t}\right)}{\operatorname{Var}\left(\Delta w_{i t}\right)}=1 .
$$

This decomposition constitutes a nice measure of how 'important' each component can be said to be for the description of the variance of wage growth. Abowd, Kramarz, and Margolis (1999) (and subsequently Abowd, Creecy, and Kramarz (2002)) make a decomposition much like this and find that the worker effect is by far the most important component in determining the variance in wage levels leaving only very little explanation to firm effects. Sørensen and Vejlin (2009) also decompose the variance of wage levels following the method of Woodcock (2008) who shows how to decompose the variance of wages when including worker fixed effects, firm fixed effects and a match specific effect. Sørensen and Vejlin use the same raw data as us but with a slightly different subgroup selection, and they include a match fixed effect besides worker and firm fixed effects. Their paper also only uses the years from 1980 to 2003 . They find that depending on skill levels, the firm effect can be said to explain from 10 to 25 per cent of the variation in wages. Furthermore, they find that the degree of explanation given by firm effects is declining when the skill level increases. Sørensen and Vejlin find the contributions to the explanation of the variance in wages given by worker effects to range from 35 per cent for low skilled workers to 45 per cent for high skilled workers.

Table 6 shows summary statistics from the AKM model estimated on wage growth and wage levels and the variance decomposition as shown above. First, turning to the model for wage levels, i.e. the standard AKM model, we find that the worker fixed effects dominates the explanation of the variance

\footnotetext{
${ }^{11}$ Note that for a normal OLS regression with regular covariates included only, $\Delta w_{i t}=x_{i t}^{\prime} \beta+\varepsilon_{i t}$ the following holds; $\frac{\operatorname{Cov}\left(\Delta w_{i t}, x_{i t}^{\prime} \hat{\beta}\right)}{\operatorname{Var}\left(\Delta w_{i t}\right)}=1-\frac{\operatorname{Cov}\left(\Delta w_{i t}, \hat{\varepsilon}\right)}{\operatorname{Var}\left(\Delta w_{i t}\right)}=R^{2}$.
} 
of wages explaining around 58 percent of wage variation in the estimation on the full sample. The firm fixed effects contribute with 14 percent, while experience and year fixed effects (put together into $X \beta$ ) contribute with 9 percent. However, turning to the subgroup analysis we find that the worker fixed effect mostly dominate for high educated, while for low educated the worker and firm fixed effects are almost equally important. It seems that the heterogeneity in the explanatory power of each is completely based on education and not on gender, even though, of course, there are small differences between men and women. Sørensen and Vejlin (2009) also find nearly the same contributions from firm fixed effects while our worker effects contribute with more to the explanation of the variance in wages. Our covariates (experience and year effects) contribute with much less than what Sørensen and Vejlin find. This difference can be explained by their inclusion of a match effect and a slightly different sample selection. Sørensen and Vejlin (2009) also find the same pattern in the subgroup analysis. Thus, the sample select seems to be able to produce results in the same range as known in the literature.

Our results of the variance decomposition thus yield much lower estimates of the degree of explanation of the variance in wage levels than those given by most former literature. One explanation of this can be that we use much longer panels than e.g. Abowd, Kramarz, and Margolis (1999) (panel covering 1976-1987, excluding 1981 and 1983), Abowd, Creecy, and Kramarz (2002) (same panel length as AKM) and Barth and Dale-Olsen (2003) (panel covering 1989-1997). Figures 2 to 4 show the variance decomposition (equation (6)) plotted for each subgroup against the number of times we have observed the individual worker. The development in contribution to the variance of wages is almost the same for all three subgroups where the worker effects seem to be mostly negatively affected by the length of the panels while the contributions from firm effects are relatively constant and the covariates experience increasing contribution to the variance of wages for all subgroups. AKM, Abowd et. al, and Barth and Dale-Olsen all use unbalanced panels as we do, and they could thus possibly have an upward biased worker effect. It is a subject for further research whether the estimated worker and firm effects are dependent on the panel lengths at hand.

Now turning to the main analysis of the wage growth equation. For the full sample the variation in the worker effect explains 8.7 percent, the firm effect explains 4.2 percent, and experience and year effects explain 2.2 percent. I.e., as in the regressions on wage levels, the most important component is the worker fixed effect. When we estimate the model on the six subgroups of gender and educational level an interesting pattern emerges. It seems that especially the worker effect, but to some extent 
also the firm effect, is more important in explaining women's wage growth. In all subgroups with an equal amount of education the explanatory power of both the worker and the firm effect is higher for women than for men. The clear pattern from the wage level estimation, where worker effects were most important for high educated, is nearly not present in for wage growth. In general, worker effects explain around 8 to 12 per cent, firm effects explain around 4 to 10 per cent, and experience and the year dummies together explain 2 to 3 per cent. That is, the most important component of wage growth is worker specific differences, but it also seems that firm heterogeneity plays a relatively important role in determining wage growth compared to determining variance in wage levels. We also see that experience and year dummies explain a very small fraction of the variation in wage growth. This is not a surprising result though, since (in the Robustness section below (table 8 column (1))) we find $R^{2}=0.024$ when running a simple OLS regression without including any fixed effects.

Compared to the model for wage levels the degree of explanation is dramatically smaller for wage growth. I.e. we cannot explain the variation in wage growth as precisely as we can explain the variation in the level of wages. Also for wage levels the most important component is the worker fixed effect, while the firm fixed effect and experience and year dummies seem to explain an almost equal share. The latter part is in contrast to the model for wage growth where the covariates constantly contribute with around half the share of the contribution given by firm fixed effects. Furthermore, given the relatively low contribution given by firm effects compared to the worker effects and the residual could make one doubt the significance of the firm effects. We have tested this for each subgroup using a simple F-test with the hypothesis that the model with firm effects included does not provide a significant better fit of wage growth (and levels) than a model without firm fixed effects included. The test gives a p-value of zero for all subgroups for both wage growth and wage levels. ${ }^{12}$

Table 7 shows the correlation structure of the two models for wage growth and wage levels. In levels we see that there is a small but positive correlation between the firm effect and the worker effect in the full sample, but when we turn to the subsamples we find a negative correlation. This is also found by Sørensen and Vejlin (2009). In the wage growth equation we find a strong negative correlation between the firm effect and the worker effect. I.e. workers with high wage growth are on average in firms with low wage growth. One reason could be the negative bias between worker and firm effects, see e.g. Bagger and Lentz (2008). This negative correlation between worker and firm effects

\footnotetext{
${ }^{12}$ The test with the lowest $\mathrm{F}$-statistic is high educated women, wage growth at $F=52,393$. The corresponding critical value on a significance level of five per cent is $F(92,036-20,277 ; 450,948-20,277)=1.009$ and the firm effects are thus highly significant.
} 
is consistently stronger for women than for men throughout the educational subgroups, and does not differ much for men whether they are high, medium or low educated, whereas the correlation is much higher (in absolute terms) for high educated women than for low and medium educated women.

\section{Robustness}

To analyze the robustness of our results we have run several different specifications of the model. First, to check if the low contribution in the wage growth variance decomposition by covariates results from too few variables added, we have included information on marital status, children, the size of the firm this period and one period before to the covariates. Second, we regress seven different variations of the model to see if the results change between them. Table 8 shows these robustness checks. Column (3) is the baseline model where the only difference compared to the full sample part of table 6 (row $2-6)$ is that a very small fraction of the worker effect and the residuals has been absorbed by the covariates with the inclusion of the extra variables. The difference between column (3) and the full sample part of table 6 is not significant on any conventional levels, though, and we have thus no reason to think that excluding the extra covariates alters our results. ${ }^{13}$ Column (1) is the original OLS regression and the covariates themselves are seen to explain 2.24 per cent of the variance in wage growth; The same contribution up to four decimals as in the baseline model with both worker and firm fixed effects added. We thus seem to be able to extract truly unobserved heterogeneity by including the fixed effects. The importance of the covariates does not alter much if we include either firm effects (column (2)) or worker effects (column (6)) to the model only, and lies between 2.1 and 2.9 per cent. The contribution from the unobserved worker heterogeneity on the variance of wage growth is relatively robust over columns (3) to (6) but the importance of the unobserved firm heterogeneity seems to increase for models with worker fixed effects included (columns (3) and (5)) than without worker specific effects (columns (2) and (7)). In the end, our model specification seems to be relatively robust.

Table 9 and 10 list the same robustness checks as table 8 but for growth in wages over two and three periods respectively. Comparing the baseline model (column (3)) in table 9 and 10 with table 6 shows that the interrelationship between the worker fixed effects, the firm fixed effects and the covariates remains relatively constant with the firm effects being twice as important as the covariates and the worker effects again twice as important as the firm effects. When analyzing higher period

\footnotetext{
${ }^{13}$ The F-value of a test between the two models is 1,079.8 and is thus not close of being significant.
} 
wage growth one would expect the different components to absorb some of the residual explanation compared to one-period wage growth; the covariates because experience increases. the firm effect because firms paying consistently higher than average period-to-period wage growth will be paying even higher two-period wage growth. Finally, the worker effect will follow a similar pattern and be more important for describing the variance in wage growth over two periods than in only one period. Likewise, these effects would be expected to be even more clear when analyzing wage growth over three periods. Table 9 and 10 indeed show that the contribution to the variance in wage growth rises when moving from one-period to two- and three-period wage growth as we would expect. However, it is important to note that the relative contribution does not change much.

\section{Conclusion}

This paper estimates a regression model for individual wage growth incorporating fixed worker and firm effects. We find that these worker and firm fixed effects influence wage growth very differently from the way they influence wages in levels. We have decomposed the variance of wage growth and wage levels into contributions from fixed worker effects, fixed firm effects, observable experience and year effects and what is left unexplained. We found that while worker effects could contribute with around 60 per cent for high educated workers, around 42 per cent for medium educated workers and around 35 percent for low educated workers of the variance in wage levels we are only able to attribute around 7 to 12 per cent to worker effects for all three educational groups of the variance in wage growth to fixed worker effects. The same pattern seems to be the case for firm effects, for which we can attribute from 10 to 30 per cent of the contribution to the variance in wage levels, while they are estimated to explain 4 to 10 per cent of the variance in wage growth. Finally, the amount of variance left unexplained is much higher for wage growth than it is for wage levels ranging from 76 per cent to 85 per cent for subgroups and 85 per cent for the full sample in wage growth versus 14 to 25 per cent for subgroups and 19 per cent for the full sample in wage levels.

However, the amount of variance that we can explain increases from 15 per cent to 30 per cent, when we use three-period wage growth instead of one-period growth. Importantly, the interrelationship between the components does not alter considerably when moving from using one-period wage growth to either two- or three-period wage growth, as the worker effect keeps having around twice the explanatory power as firm effects which then have almost twice the explanatory power as observable covariates. 
We also find a very strong negative correlation between fixed worker and fixed firm effects in wage growth.

\section{References}

Abowd, J., H. Finer, and F. Kramarz (1999): "Individual and Firm Heterogeneity in Compensation: An Analysis of Matched Longitudinal Employer and Employee Data for the State of Washington," in The Creation and Analysis of Employer-Employee Matched Data, ed. by J. Haltiwanger, J. Lane, J. Spletzer, and K. Troske, pp. 3-24. North-Holland.

Abowd, J. M., R. H. Creecy, and F. Kramarz (2002): "Computing Person and Firm Effects Using Linked Longitudinal Employer-Employee Data," Technical Paper 2002-06, U.S. Census Bureau.

Abowd, J. M., And F. Kramarz (1999): The Analysis of Labor Markets using Matched EmployerEmployee Data vol. 3, chap. 40, pp. 2629-2710. Handbook of Labor Economics, Elsevier Science B.V.

Abowd, J. M., F. Kramarz, and D. N. Margolis (1999): "High Wage Workers and High Wage Firms," Econometrica, 67(2), 251-333.

Andrews, M. J., L. Gill, T. Schank, and R. Upward (2008): "High wage workers and low wage firms: negative assortative matching or limited mobility bias?," Journal of the Royal Statistical Society, A(2008) 171(Part 3), 673-697.

Bagger, J., F. Fontaine, F. Postel-Vinay, and J.-M. Robin (2007): "A Tractable Equilibrium Search Model with Experience Accumulation," Working Paper.

Bagger, J., And R. Lentz (2008): “An Empirical Model of Wage Dispersion with Sorting,” Working Paper.

Barth, E., And H. Dale-Olsen (2003): "Assortative matching in the labor market? Stylized facts about workers and plants," Institute for Social Research, Oslo, Norway.

Connolly, H., and P. Gottschalk (2006): "Differences in Wage Growth by Education Level: Do Less-Educated Workers Gain Less from Work Experience?," IZA Discussion Papers 2331, Institute for the Study of Labor (IZA). 
Eeckhout, J., And P. Kircher (2009): "Identifying Sorting - In Theory," Working Paper.

Gruetter, M., and R. Lalive (2004): "The Importance of Firms in Wage Determination," IEW Working Papers 207, Institute for Empirical Research in Economics - IEW.

Heckman, J. J., L. J. Lochner, and P. E. Todd (2003): "Fifty Years of Mincer Earnings Regressions," NBER Working Papers 9732, National Bureau of Economic Research, Inc.

Kramarz, F., S. Machin, and A. Ouazad (2009): "What Makes a Test Score? The Respective Contributions of Pupils, Schools and Peers in Achievement in English Primary Education," CEE Discussion Papers CEEDP0102, CEE.

Lopes De Melo, R. (2008): "Sorting In the Labor Market: Theory and Measurement," Working Paper, Yale.

Mincer, J. (1958): "Investment in Human Capital and Personal Income Distribution," The Journal of Political Economy, 66(4), 281-302.

Mincer, J. A. (1974): Schooling, Experience, and Earnings. National Bureau of Economic Research, Inc.

Mortensen, D. T. (2005): Wage Dispersion - Why are similar workers paid differently. First MIT Press paperback edition.

Postel-Vinay, F., And J.-M. Robin (2002): "Equilibrium Wage Dispersion with Worker and Employer Heterogeneity," Econometrica, 70(6), 2295-2350.

Shimer, R. (2005): "The Assignment of Workers in an Economy with Coordination Frictions," Journal of Political Economy, 113(5).

Sørensen, T., And R. VeJlin (2009): "The importance of worker, firm and match fixed effects in wage regressions," Working Paper - Aarhus University.

Woodcock, S. (2008): "Match Effects," Discussion Papers. Department of Economics, Simon Fraser University. 
Table 1: Descriptive statistics merging from the grouping algorithm.

\begin{tabular}{|c|c|c|c|c|c|}
\hline & $\begin{array}{c}\text { Number of } \\
\text { observations }\end{array}$ & $\begin{array}{r}\text { Number of } \\
\text { workers }\end{array}$ & $\begin{array}{r}\text { Number of } \\
\text { firms }\end{array}$ & $\begin{array}{r}\text { Number of } \\
\text { groups }\end{array}$ & $\begin{array}{r}\text { Number of } \\
\text { estimable effects }\end{array}$ \\
\hline \multirow[t]{2}{*}{ Full sample } & $20,836,823$ & $2,116,094$ & 322,802 & 24,793 & $2,414,103$ \\
\hline & $(20,703,609)$ & $(2,083,391)$ & $(295,034)$ & (1) & $(2,378,424)$ \\
\hline \multicolumn{6}{|l|}{ Men } \\
\hline \multirow[t]{2}{*}{ High educ. } & $1,750,247$ & 179,108 & 59,733 & 9,270 & 229,571 \\
\hline & $(1,682,834)$ & $(166,827)$ & $(47,019)$ & (1) & $(213,845)$ \\
\hline \multirow[t]{2}{*}{ Medium educ. } & $8,912,263$ & 798,308 & 217,298 & 15,671 & 999,935 \\
\hline & $(8,823,828)$ & $(780,009)$ & $(198,844)$ & (1) & $(978,852)$ \\
\hline \multirow[t]{2}{*}{ Low educ. } & $4,074,495$ & 401,943 & 147,853 & 14,171 & 535,625 \\
\hline & $(3,996,477)$ & $(385,574)$ & $(129,944)$ & (1) & $(515,517)$ \\
\hline \multirow[t]{2}{*}{ Total } & $15,737,005$ & $1,379,359$ & 424,884 & 39,112 & $1,765,131$ \\
\hline & $(14,503,139)$ & $(1,332,410)$ & $(375,807)$ & (3) & $(1,708,214)$ \\
\hline \multicolumn{6}{|l|}{ Women } \\
\hline \multirow[t]{2}{*}{ High educ. } & 515,512 & 87,387 & 33,262 & 9,715 & 110,934 \\
\hline & $(450,948)$ & $(71,760)$ & $(20,277)$ & (1) & $(92,036)$ \\
\hline \multirow[t]{2}{*}{ Medium educ. } & $3,555,893$ & 404,602 & 139,539 & 18,360 & 525,781 \\
\hline & $(3,443,791)$ & $(382,385)$ & $(116,365)$ & (1) & $(498,749)$ \\
\hline \multirow[t]{2}{*}{ Low educ. } & $2,028,413$ & 244,746 & 95,732 & 18,693 & 321,785 \\
\hline & $(1,914,928)$ & $(222,350)$ & $(71,028)$ & (1) & $(293,377)$ \\
\hline \multirow[t]{2}{*}{ Total } & $6,099,818$ & 736,735 & 268,533 & 46,768 & 958,500 \\
\hline & $(5,809,667)$ & $(676,495)$ & $(207,670)$ & $(3)$ & $(884,162)$ \\
\hline
\end{tabular}

Note: The figures from the largest group of each sample are in parenthesis.

Note, furthermore, that a firm can be in more than one sample, so a firm can be present up to three times in the total number of firms and estimable effects. 
Table 2: Costs in terms of observations when narrowing down the sample.

\begin{tabular}{lrl}
\hline & Observation & \multicolumn{1}{l}{$\begin{array}{l}\text { Sample } \\
\text { Correction }\end{array}$} \\
\hline Population & & \multicolumn{1}{l}{ size } \\
Missing education information & $1,256,538$ & $50,847,593$ \\
Labor market entry & $11,064,910$ & $48,526,145$ \\
Private sector & $18,207,737$ & $30,318,408$ \\
Students & 983,862 & $29,334,546$ \\
Experience outliers & 15,168 & $29,319,378$ \\
Full-time employment & $2,402,026$ & $26,917,352$ \\
Non-positive hourly wages & 65,571 & $26,851,781$ \\
Non-credible hours & $1,115,560$ & $25,736,221$ \\
Wages below P1 & 248,899 & $25,487,322$ \\
Wages above P99 & 254,555 & $25,232,767$ \\
First worker-obs and missing year & $4,395,944$ & $20,836,823$ \\
\hline
\end{tabular}

Table 3: Descriptive Statistics of Labor Market Experience

\begin{tabular}{lcccccc}
\hline & Mean & Median & Std. dev. & P10 & P90 & Total observations \\
\hline Full sample & 16.65 & 16.00 & 8.54 & 5.87 & 28.56 & $20,836,823$ \\
& & & & & & \\
Men & & & & & & $1,750,247$ \\
High edu. & 16.21 & 15.50 & 8.68 & 5.24 & 28.33 & $8,912,263$ \\
Medium edu. & 17.52 & 17.00 & 8.48 & 6.75 & 29.20 & $4,074,495$ \\
Low edu. & 17.74 & 17.89 & 8.84 & 5.81 & 29.80 & $14,737,005$ \\
Total & 17.43 & 17.00 & 8.61 & 6.32 & 29.23 & \\
& & & & & & $5,515,512$ \\
Women & & & & & & $2,028,413$ \\
High edu. & 12.8 & 11.00 & 7.96 & 3.88 & 24.55 & $6,099,818$ \\
Medium edu. & 15.01 & 13.89 & 8.14 & 5.25 & 26.67 & \\
Low edu. & 14.91 & 14.18 & 7.85 & 4.97 & 25.85 & \\
Total & 14.79 & 13.77 & 8.05 & 5.00 & 26.07 & \\
\hline
\end{tabular}


Table 4: Number of Observations per Worker

\begin{tabular}{|c|c|c|c|c|c|c|c|c|}
\hline & Average & 1 & 2 & $3-5$ & $6-10$ & $11-20$ & $21+$ & Total workers \\
\hline \multirow[t]{2}{*}{ Full sample } & 9.85 & 221,977 & 167,198 & 386,807 & 499,124 & 584,950 & 256,038 & $2,116,094$ \\
\hline & & $(0.1049)$ & $(0.0790)$ & $(0.1828)$ & $(0.2359)$ & $(0.2764)$ & $(0.1210)$ & \\
\hline \multicolumn{9}{|l|}{ Men } \\
\hline \multirow[t]{2}{*}{ High edu. } & 9.77 & 17,585 & 13,741 & 32,480 & 44,762 & 50,926 & 19,614 & 179,108 \\
\hline & & $(0.0982)$ & $(0.0767)$ & $(0.1813)$ & $(0.2499)$ & $(0.2843)$ & $(0.1095)$ & \\
\hline \multirow[t]{2}{*}{ Medium edu. } & 11.16 & 61,566 & 50,807 & 126,284 & 183,109 & 248,180 & 128,362 & 798,308 \\
\hline & & $(0.0771)$ & $(0.0636)$ & $(0.1582)$ & $(0.2294)$ & $(0.3109)$ & $(0.1608)$ & \\
\hline \multirow[t]{2}{*}{ Low edu. } & 10.14 & 41,977 & 31,275 & 70,589 & 93,081 & 109,897 & 55,124 & 401,943 \\
\hline & & $(0.1044)$ & $(0.0778)$ & $(0.1756)$ & $(0.2316)$ & $(0.2734)$ & $(0.1371)$ & \\
\hline \multirow[t]{2}{*}{ Total } & & 121,128 & 95,823 & 229,353 & 320,952 & 409,003 & 203,100 & $1,379,359$ \\
\hline & & $(0.0878)$ & $(0.0695)$ & $(0.1663)$ & $(0.2327)$ & $(0.2965)$ & $(0.1472)$ & \\
\hline \multicolumn{9}{|l|}{ Women } \\
\hline \multirow[t]{2}{*}{ High edu. } & 5.90 & 16,977 & 11,562 & 22,557 & 22,204 & 12,345 & 1,742 & 87,387 \\
\hline & & $(0.1943)$ & $(0.1323)$ & $(0.2581)$ & $(0.2541)$ & $(0.1413)$ & $(0.0199)$ & \\
\hline \multirow[t]{2}{*}{ Medium edu. } & 8.79 & 48,775 & 35,616 & 83,420 & 98,159 & 106,227 & 32,405 & 404,602 \\
\hline & & $(0.1206)$ & $(0.0880)$ & $(0.2062)$ & $(0.2426)$ & $(0.2625)$ & $(0.0801)$ & \\
\hline \multirow[t]{2}{*}{ Low edu. } & 8.29 & 35,097 & 24,197 & 51,477 & 57,809 & 57,375 & 18,791 & 244,746 \\
\hline & & $(0.1434)$ & $(0.0989)$ & $(0.2103)$ & $(0.2362)$ & $(0.2344)$ & $(0.0768)$ & \\
\hline \multirow[t]{2}{*}{ Total } & & 100,849 & 71,375 & 157,454 & 178,172 & 175,947 & 52,938 & 736,735 \\
\hline & & $(0.1369)$ & $(0.0969)$ & $(0.2137)$ & $(0.2418)$ & $(0.2388)$ & $(0.0719)$ & \\
\hline
\end{tabular}

Note: Numbers in parenthesizes denote percentages of subsamples. 
Table 5: Number of Employers per Worker

\begin{tabular}{|c|c|c|c|c|c|c|c|c|}
\hline & Average & 1 & 2 & 3 & 4 & $5-10$ & $11+$ & Total workers \\
\hline Full sample & 2.52 & $\begin{array}{l}772,003 \\
(0.3648)\end{array}$ & $\begin{array}{l}501,601 \\
(0.2370)\end{array}$ & $\begin{array}{l}345,654 \\
(0.1634)\end{array}$ & $\begin{array}{l}231,683 \\
(0.1095)\end{array}$ & $\begin{array}{l}262,153 \\
(0.1239)\end{array}$ & $\begin{array}{c}3,000 \\
(0.0014)\end{array}$ & $2,116,094$ \\
\hline \multicolumn{9}{|l|}{ Men } \\
\hline High edu. & 2.44 & $\begin{array}{c}67,199 \\
(0.3752)\end{array}$ & $\begin{array}{c}43,441 \\
(0.2425)\end{array}$ & $\begin{array}{c}29,463 \\
(0.1645)\end{array}$ & $\begin{array}{c}18,573 \\
(0.1037)\end{array}$ & $\begin{array}{c}20,313 \\
(0.1134)\end{array}$ & $\begin{array}{c}119 \\
(0.0007)\end{array}$ & 179,108 \\
\hline Medium edu. & 2.80 & $\begin{array}{l}238,394 \\
(0.2986)\end{array}$ & $\begin{array}{l}186,110 \\
(0.2332)\end{array}$ & $\begin{array}{l}142,408 \\
(0.1784)\end{array}$ & $\begin{array}{c}101,481 \\
(0.1271)\end{array}$ & $\begin{array}{l}128,142 \\
(0.1605)\end{array}$ & $\begin{array}{c}1,773 \\
(0.0022)\end{array}$ & 798,308 \\
\hline Low edu. & 2.63 & $\begin{array}{c}144,643 \\
(0.3599)\end{array}$ & $\begin{array}{c}89,662 \\
(0.2230)\end{array}$ & $\begin{array}{c}63,678 \\
(0.1584)\end{array}$ & $\begin{array}{c}45,311 \\
(0.1127)\end{array}$ & $\begin{array}{c}57,739 \\
(0.1437)\end{array}$ & $\begin{array}{c}910 \\
(0.0023)\end{array}$ & 401,943 \\
\hline Total & & $\begin{array}{l}450,236 \\
(0.3264)\end{array}$ & $\begin{array}{l}319,213 \\
(0.2314)\end{array}$ & $\begin{array}{l}235,549 \\
(0.1708)\end{array}$ & $\begin{array}{l}165,365 \\
(0.1199)\end{array}$ & $\begin{array}{l}206,194 \\
(0.1495)\end{array}$ & $\begin{array}{c}2,802 \\
(0.0020)\end{array}$ & $1,379,359$ \\
\hline \multicolumn{9}{|l|}{ Women } \\
\hline High edu. & 1.77 & $\begin{array}{c}50,603 \\
(0.5790)\end{array}$ & $\begin{array}{c}19,494 \\
(0.2231)\end{array}$ & $\begin{array}{c}9,459 \\
(0.1082)\end{array}$ & $\begin{array}{c}4,491 \\
(0.0514)\end{array}$ & $\begin{array}{c}3,336 \\
(0.0382)\end{array}$ & $\begin{array}{c}4 \\
(0.0001)\end{array}$ & 87,387 \\
\hline Medium edu. & 2.31 & $\begin{array}{l}157,558 \\
(0.3894)\end{array}$ & $\begin{array}{l}103,714 \\
(0.2563)\end{array}$ & $\begin{array}{c}66,414 \\
(0.1642)\end{array}$ & $\begin{array}{c}40,898 \\
(0.1011)\end{array}$ & $\begin{array}{c}35,889 \\
(0.0887)\end{array}$ & $\begin{array}{c}129 \\
(0.0003)\end{array}$ & 404,602 \\
\hline Low edu. & 2.10 & $\begin{array}{l}113,606 \\
(0.4642)\end{array}$ & $\begin{array}{c}59,180 \\
(0.2418)\end{array}$ & $\begin{array}{c}34,232 \\
(0.1399)\end{array}$ & $\begin{array}{c}20,929 \\
(0.0854)\end{array}$ & $\begin{array}{c}16,734 \\
(0.0684)\end{array}$ & $\begin{array}{c}65 \\
(0.0003)\end{array}$ & 244,746 \\
\hline Total & & $\begin{array}{l}321,767 \\
(0.4367)\end{array}$ & $\begin{array}{l}182,388 \\
(0.2475)\end{array}$ & $\begin{array}{l}110,105 \\
(0.1495)\end{array}$ & $\begin{array}{c}66,318 \\
(0.0900)\end{array}$ & $\begin{array}{c}55,959 \\
(0.0760)\end{array}$ & $\begin{array}{c}198 \\
(0.0003)\end{array}$ & 736,735 \\
\hline
\end{tabular}

Note: Numbers in parenthesizes denote percentages of subsamples.

Figure 1: The distribution of wage growth for the entire sample 1980-2006.

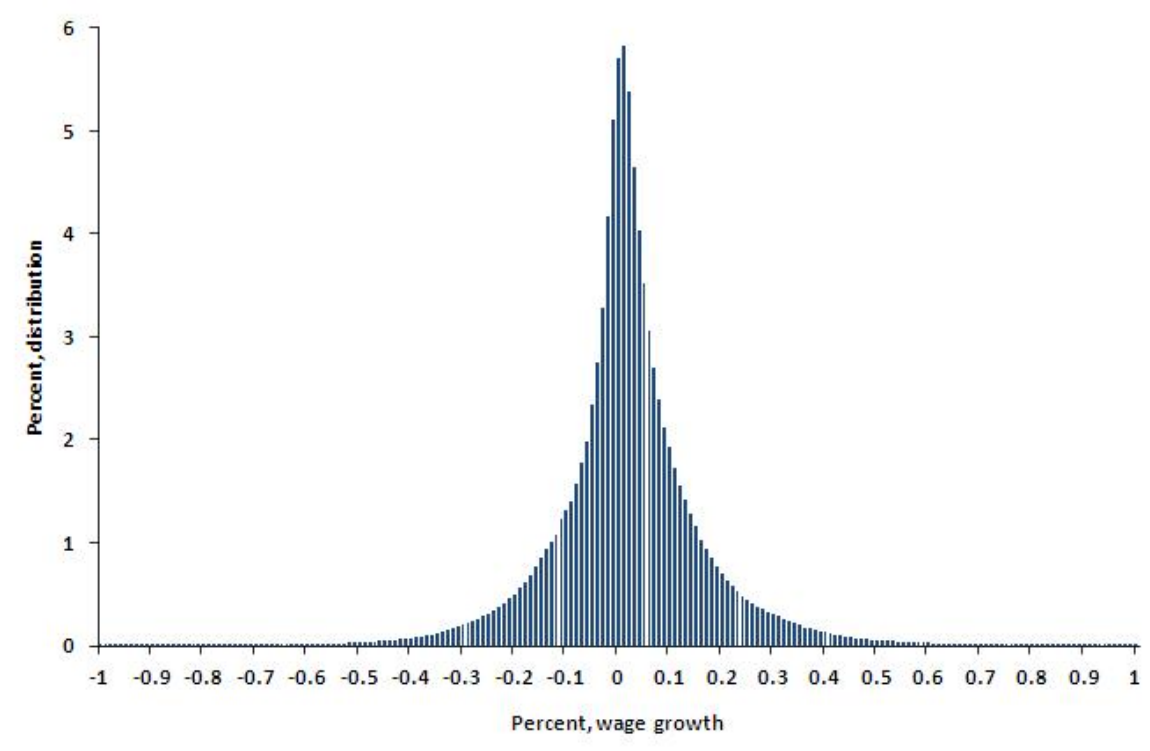


Table 6: Regression results.

\begin{tabular}{|c|c|c|c|c|c|c|c|c|}
\hline \multirow[b]{3}{*}{$\mathrm{Z}$} & \multicolumn{4}{|c|}{ Wage growth } & \multicolumn{4}{|c|}{ Wage levels } \\
\hline & & & & $\operatorname{Cov}(w, Z)$ & & & & $\operatorname{Cov}(w, Z)$ \\
\hline & Mean & Std. Dev. & $\operatorname{Cov}(w, Z)$ & $/ \operatorname{Var}(w)$ & Mean & Std. Dev. & $\operatorname{Cov}(w, Z)$ & $/ \operatorname{Var}(w)$ \\
\hline \multicolumn{9}{|c|}{ Full sample $(20,703,609$ observations $)$} \\
\hline$w$ & 0.0196 & 0.1486 & 0.0221 & 1.0000 & 5.2372 & 0.3072 & 0.0944 & 1.0000 \\
\hline$\theta$ & -0.0780 & 0.0578 & 0.0019 & 0.0868 & 4.8103 & 0.2319 & 0.0543 & 0.5752 \\
\hline$\psi$ & 0.1110 & 0.0470 & 0.0009 & 0.0415 & 0.2547 & 0.1107 & 0.0132 & 0.1399 \\
\hline $\mathrm{X} \beta$ & -0.0134 & 0.0248 & 0.0005 & 0.0218 & 0.1723 & 0.0940 & 0.0088 & 0.0927 \\
\hline$\varepsilon$ & 0.0000 & 0.1370 & 0.0188 & 0.8499 & 0.0000 & 0.1347 & 0.0181 & 0.1922 \\
\hline
\end{tabular}

High educated

Men (1,682,834 observations)

$\begin{array}{lllllllll}w & 0.0279 & 0.1537 & 0.0236 & 1.0000 & 5.6571 & 0.3354 & 0.1125 & 1.0000 \\ \theta & -0.3121 & 0.0687 & 0.0017 & 0.0739 & 5.5965 & 0.2945 & 0.0645 & 0.5732 \\ \psi & 0.3370 & 0.0673 & 0.0018 & 0.0753 & 0.1186 & 0.1392 & 0.0119 & 0.1059 \\ \mathrm{X} \beta & 0.0031 & 0.0259 & 0.0005 & 0.0216 & -0.0581 & 0.1838 & 0.0141 & 0.1255 \\ \varepsilon & 0.0000 & 0.1400 & 0.0196 & 0.8292 & 0.0000 & 0.1483 & 0.0220 & 0.1954\end{array}$

Women (450,948 observations)

$\begin{array}{lcccccccc}w & 0.0297 & 0.1482 & 0.0220 & 1.0000 & 5.4231 & 0.3104 & 0.0963 & 1.0000 \\ \theta & 0.0960 & 0.1130 & 0.0026 & 0.1161 & 5.5190 & 0.2689 & 0.0598 & 0.6208 \\ \psi & -0.0581 & 0.1106 & 0.0021 & 0.0961 & -0.0851 & 0.1451 & 0.0124 & 0.1289 \\ \mathrm{X} \beta & -0.0083 & 0.0217 & 0.0005 & 0.0208 & -0.0108 & 0.1315 & 0.0099 & 0.1031 \\ \varepsilon & 0.0000 & 0.1298 & 0.0169 & 0.7670 & 0.0000 & 0.1191 & 0.0142 & 0.1472\end{array}$

Medium educated

Men (8,823,828 observations)

$\begin{array}{lcccccccc}w & 0.0181 & 0.1488 & 0.0222 & 1.0000 & 5.2778 & 0.2633 & 0.0693 & 1.0000 \\ \theta & -0.0533 & 0.0582 & 0.0016 & 0.0712 & 4.8230 & 0.1817 & 0.0313 & 0.4513 \\ \psi & 0.0931 & 0.0546 & 0.0012 & 0.0558 & 0.2670 & 0.1199 & 0.0134 & 0.1935 \\ \mathrm{X} \beta & -0.0218 & 0.0238 & 0.0005 & 0.0220 & 0.1878 & 0.0882 & 0.0071 & 0.1025 \\ \varepsilon & 0.0000 & 0.1373 & 0.0189 & 0.8509 & 0.0000 & 0.1324 & 0.0175 & 0.2527 \\ \text { Women } & (3,443,791 \text { observations }) & & & & & & \\ w & 0.0259 & 0.1406 & 0.0198 & 1.0000 & 5.0995 & 0.2546 & 0.0648 & 1.0000 \\ \theta & -0.2304 & 0.0720 & 0.0020 & 0.1024 & 4.5700 & 0.1774 & 0.0277 & 0.4271 \\ \psi & 0.2595 & 0.0650 & 0.0013 & 0.0661 & 0.3321 & 0.1104 & 0.0103 & 0.1591 \\ \mathrm{X} \beta & -0.0032 & 0.0276 & 0.0006 & 0.0280 & 0.1974 & 0.1181 & 0.0127 & 0.1955 \\ \varepsilon & 0.0000 & 0.1260 & 0.0159 & 0.8036 & 0.0000 & 0.1190 & 0.0141 & 0.2183\end{array}$

Low educated

Men (3,996,477 observations)

\begin{tabular}{llllllllll}
$w$ & 0.0151 & 0.1554 & 0.0241 & 1.0000 & 5.1837 & 0.2447 & 0.0599 & 1.0000 \\
\hline
\end{tabular}

This table continues on the next page.

Note: $\mathrm{Z}$ in columns 4, 5, 9 and 10 denotes $w, \theta, \psi, \mathrm{X} \beta$ or $\varepsilon$ depending on the row in question. 
Table 6 - continued from previous page.

\begin{tabular}{|c|c|c|c|c|c|c|c|c|}
\hline \multirow[b]{2}{*}{ Z } & \multicolumn{4}{|c|}{ Wage growth } & \multicolumn{4}{|c|}{ Wage levels } \\
\hline & Mean & Std. Dev. & $\operatorname{Cov}(w, Z)$ & $\begin{array}{l}\operatorname{Cov}(w, Z) \\
/ \operatorname{Var}(w) \\
\end{array}$ & Mean & Std. Dev. & $\operatorname{Cov}(w, Z)$ & $\begin{array}{l}\operatorname{Cov}(w, Z) \\
/ \operatorname{Var}(w) \\
\end{array}$ \\
\hline$\theta$ & 0.0051 & 0.0720 & 0.0020 & 0.0841 & 4.6726 & 0.1620 & 0.0211 & 0.3531 \\
\hline$\psi$ & 0.0359 & 0.0704 & 0.0019 & 0.0781 & 0.3344 & 0.1432 & 0.0175 & 0.2915 \\
\hline $\mathrm{X} \beta$ & -0.0258 & 0.0275 & 0.0006 & 0.0267 & 0.1767 & 0.0783 & 0.0058 & 0.0976 \\
\hline$\varepsilon$ & 0.0000 & 0.1400 & 0.0196 & 0.8111 & 0.0000 & 0.1242 & 0.0154 & 0.2577 \\
\hline \multicolumn{9}{|c|}{ Women (1,914,928 observations) } \\
\hline$w$ & 0.0160 & 0.1376 & 0.0189 & 1.0000 & 5.0194 & 0.2277 & 0.0518 & 1.0000 \\
\hline$\theta$ & 0.0526 & 0.0785 & 0.0020 & 0.1063 & 4.7302 & 0.1593 & 0.0178 & 0.3429 \\
\hline$\psi$ & -0.0577 & 0.0738 & 0.0016 & 0.0825 & 0.1063 & 0.1420 & 0.0154 & 0.2972 \\
\hline $\mathrm{X} \beta$ & 0.0212 & 0.0279 & 0.0005 & 0.0277 & 0.1830 & 0.0853 & 0.0064 & 0.1244 \\
\hline$\varepsilon$ & 0.0000 & 0.1218 & 0.0148 & 0.7836 & 0.0000 & 0.1105 & 0.0122 & 0.2355 \\
\hline
\end{tabular}

Note: $\mathrm{Z}$ in columns $4,5,9$ and 10 denotes $w, \theta, \psi, \mathrm{X} \beta$ or $\varepsilon$ depending on the row in question. 
Table 7: Correlation structure, full AKM model, wage growth and wage levels.

\begin{tabular}{|c|c|c|c|c|c|c|c|c|c|c|}
\hline & \multicolumn{5}{|c|}{ Wage growth } & \multicolumn{5}{|c|}{ Wage levels } \\
\hline & $w$ & $\theta$ & $\psi$ & $\mathrm{X} \beta$ & $\varepsilon$ & $w$ & $\theta$ & $\psi$ & $\mathrm{X} \beta$ & $\varepsilon$ \\
\hline \multicolumn{11}{|c|}{ Full sample } \\
\hline$w$ & 1.0000 & 0.2232 & 0.1313 & 0.1306 & 0.9219 & 1.0000 & 0.7619 & 0.3883 & 0.3029 & 0.4384 \\
\hline$\theta$ & 0.2232 & 1.0000 & -0.4749 & -0.0931 & 0.0000 & 0.7619 & 1.0000 & 0.0302 & -0.0124 & 0.0000 \\
\hline$\psi$ & 0.1313 & -0.4749 & 1.0000 & -0.0008 & 0.0000 & 0.3883 & 0.0302 & 1.0000 & 0.0169 & 0.0000 \\
\hline $\mathrm{X} \beta$ & 0.1306 & -0.0931 & -0.0008 & 1.0000 & 0.0000 & 0.3029 & -0.0124 & 0.0169 & 1.0000 & 0.0000 \\
\hline$\varepsilon$ & 0.9219 & 0.0000 & 0.0000 & 0.0000 & 1.0000 & 0.4384 & 0.0000 & 0.0000 & 0.0000 & 1.0000 \\
\hline
\end{tabular}

High educated

Men

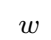

$\theta$

$\psi$

$\mathrm{X} \beta$

$\varepsilon$

Women

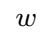

$\theta$

$\psi$

$\mathrm{X} \beta$

$\varepsilon$

$\begin{array}{lllll}1.0000 & 0.1652 & 0.1720 & 0.1285 & 0.9106 \\ 0.1652 & 1.0000 & -0.6020 & -0.1089 & 0.0000 \\ 0.1720 & -0.6020 & 1.0000 & 0.0198 & 0.0000 \\ 0.1285 & -0.1089 & 0.0198 & 1.0000 & 0.0000 \\ 0.9106 & 0.0000 & 0.0000 & 0.0000 & 1.0000 \\ & & & & \\ 1.0000 & 0.1523 & 0.1288 & 0.1422 & 0.8758 \\ 0.1523 & 1.0000 & -0.8131 & -0.0229 & 0.0000 \\ 0.1288 & -0.8131 & 1.0000 & 0.0178 & 0.0000 \\ 0.1422 & -0.0229 & 0.0178 & 1.0000 & 0.0000 \\ 0.8758 & 0.0000 & 0.0000 & 0.0000 & 1.0000\end{array}$

Medium educated

Men

$w$

$\theta$

$\psi$

$\mathrm{X} \beta$

$\varepsilon$

Women

$w$

$\theta$

$\psi$

$\mathrm{X} \beta$

$\varepsilon$

$\begin{array}{lllll}1.0000 & 0.1821 & 0.1523 & 0.1379 & 0.9225 \\ 0.1821 & 1.0000 & -0.5467 & -0.0523 & 0.0000 \\ 0.1523 & -0.5467 & 1.0000 & -0.0039 & 0.0000 \\ 0.1379 & -0.0523 & -0.0039 & 1.0000 & 0.0000 \\ 0.9225 & 0.0000 & 0.0000 & 0.0000 & 1.0000 \\ & & & & \\ 1.0000 & 0.1999 & 0.1429 & 0.1428 & 0.896 \\ 0.1999 & 1.0000 & -0.6275 & -0.1128 & 0.0000 \\ 0.1429 & -0.6275 & 1.0000 & 0.0098 & 0.0000 \\ 0.1428 & -0.1128 & 0.0098 & 1.0000 & 0.0000 \\ 0.8964 & 0.0000 & 0.0000 & 0.0000 & 1.0000\end{array}$

1.000

$1.0000 \quad 0.6528$

0.2551

0.2290

0.4420

$0.6528 \quad 1.0000$

$-0.1225$

$-0.3182$

0.0000

$0.2551 \quad-0.1225$

1.0000

$-0.0955$

0.0000

$0.2290 \quad-0.3182$

$-0.0955$

1.0000

0.0000

$0.4420 \quad 0.0000$

0.0000

0.0000

1.0000

$1.0000 \quad 0.7165$

$0.7165 \quad 1.0000$

0.2756

0.2434

0.3837

$0.2756-0.1768$

$-0.1768$

$-0.1589$

0.0000

$0.2434 \quad-0.1589$

1.0000

$-0.0911$

0.0000

$0.3837 \quad 0.0000$

$-0.0911 \quad 1.0000$

0.0000

$0.0000 \quad 0.0000$

1.0000

Low educated

Men

\begin{tabular}{llllllllllll}
$w$ & 1.0000 & 0.1816 & 0.1723 & 0.1512 & 0.9006 & 1.0000 & 0.5333 & 0.4983 & 0.3048 & 0.5077 \\
$\theta$ & 0.1816 & 1.0000 & -0.6030 & -0.0478 & 0.0000 & 0.5333 & 1.0000 & -0.1693 & -0.0927 & 0.0000 \\
$\psi$ & 0.1723 & -0.6030 & 1.0000 & -0.0077 & 0.0000 & 0.4983 & -0.1693 & 1.0000 & 0.0786 & 0.0000 \\
\hline
\end{tabular}

This table continues on the next page. 
Table 7 - continued from previous page.

\begin{tabular}{|c|c|c|c|c|c|c|c|c|c|c|}
\hline & \multicolumn{5}{|c|}{ Wage growth } & \multicolumn{5}{|c|}{ Wage levels } \\
\hline & $w$ & $\theta$ & $\psi$ & $\mathrm{X} \beta$ & $\varepsilon$ & $w$ & $\theta$ & $\psi$ & $\mathrm{X} \beta$ & $\varepsilon$ \\
\hline $\mathrm{X} \beta$ & 0.1512 & -0.0478 & -0.0077 & 1.0000 & 0.0000 & 0.3048 & -0.0927 & 0.0786 & 1.0000 & 0.0000 \\
\hline$\varepsilon$ & 0.9006 & 0.0000 & 0.0000 & 0.0000 & 1.0000 & 0.5077 & 0.0000 & 0.0000 & 0.0000 & 1.0000 \\
\hline \multicolumn{11}{|c|}{ Women } \\
\hline$w$ & 1.0000 & 0.1862 & 0.1537 & 0.1366 & 0.8852 & 1.0000 & 0.4901 & 0.4764 & 0.3319 & 0.4853 \\
\hline$\theta$ & 0.1862 & 1.0000 & -0.6717 & -0.1175 & 0.0000 & 0.4901 & 1.0000 & -0.2549 & -0.1348 & 0.0000 \\
\hline$\psi$ & 0.1537 & -0.6717 & 1.0000 & 0.0015 & 0.0000 & 0.4764 & -0.2549 & 1.0000 & 0.0826 & 0.0000 \\
\hline $\mathrm{X} \beta$ & 0.1366 & -0.1175 & 0.0015 & 1.0000 & 0.0000 & 0.3319 & -0.1348 & 0.0826 & 1.0000 & 0.0000 \\
\hline$\varepsilon$ & 0.8852 & 0.0000 & 0.0000 & 0.0000 & 1.0000 & 0.4853 & 0.0000 & 0.0000 & 0.0000 & 1.0000 \\
\hline
\end{tabular}

Table 8: Results from the wage growth variance decomposition for different models.

\begin{tabular}{|c|c|c|c|c|c|c|c|}
\hline & \multicolumn{7}{|c|}{ Degree of contribution to the variance of wage growth } \\
\hline & $(1)$ & $(2)$ & $(3)$ & $(4)$ & $(5)$ & (6) & $(7)$ \\
\hline$\theta$ & - & - & 0.0864 & 0.0890 & 0.0872 & 0.0905 & - \\
\hline$\psi$ & - & 0.0352 & 0.0415 & - & 0.0436 & - & 0.0377 \\
\hline$X \beta$ & 0.0224 & 0.0292 & 0.0224 & - & - & 0.0212 & - \\
\hline \multirow[t]{2}{*}{$\varepsilon$} & 0.9776 & 0.9356 & 0.8497 & 0.9110 & 0.8692 & 0.8883 & 0.9623 \\
\hline & \multicolumn{7}{|c|}{ Components included } \\
\hline$\theta$ & no & no & yes & yes & yes & yes & no \\
\hline$\psi$ & no & yes & yes & no & yes & no & yes \\
\hline$X \beta$ & yes & yes & yes & no & no & yes & no \\
\hline Observations & $20,703,609$ & $20,703,609$ & $20,703,609$ & $20,703,609$ & $20,703,609$ & $20,703,609$ & $20,703,609$ \\
\hline Workers & $2,083,391$ & $2,083,391$ & $2,083,391$ & $2,083,391$ & $2,083,391$ & $2,083,391$ & $2,083,391$ \\
\hline Firms & 295,034 & 295,034 & 295,034 & 295,034 & 295,034 & 295,034 & 295,034 \\
\hline Covariates & 7 & 7 & 7 & 0 & 0 & 7 & 0 \\
\hline
\end{tabular}

Note: Covariates included are; Experience, experience squared, married, children, firm size, lagged firm size and year dummies. 
Table 9: Results from the two-period wage growth variance decomposition for different models.

\begin{tabular}{|c|c|c|c|c|c|c|c|}
\hline & \multicolumn{7}{|c|}{ Degree of contribution to the variance of two-period wage growth } \\
\hline & (1) & $(2)$ & $(3)$ & $(4)$ & $(5)$ & (6) & (7) \\
\hline$\theta$ & - & - & 0.1231 & 0.1245 & 0.1221 & 0.1327 & - \\
\hline$\psi$ & - & 0.0554 & 0.0645 & - & 0.0706 & - & 0.0601 \\
\hline$X \beta$ & 0.0269 & 0.0416 & 0.0317 & - & - & 0.0297 & - \\
\hline \multirow[t]{2}{*}{$\varepsilon$} & 0.9731 & 0.9030 & 0.7807 & 0.8755 & 0.8073 & 0.8376 & 0.9399 \\
\hline & \multicolumn{7}{|c|}{ Components included } \\
\hline$\theta$ & no & no & yes & yes & yes & yes & no \\
\hline$\psi$ & no & yes & yes & no & yes & no & yes \\
\hline$X \beta$ & yes & yes & yes & no & no & yes & no \\
\hline Observations & $19,583,137$ & $19,583,137$ & $19,583,137$ & $19,583,137$ & $19,583,137$ & $19,583,137$ & $19,583,137$ \\
\hline Workers & $1,865,333$ & $1,865,333$ & $1,865,333$ & $1,865,333$ & $1,865,333$ & $1,865,333$ & $1,865,333$ \\
\hline Firms & 276,391 & 276,391 & 276,391 & 276,391 & 276,391 & 276,391 & 276,391 \\
\hline Covariates & 3 & 3 & 3 & 0 & 0 & 3 & 0 \\
\hline
\end{tabular}

Note: Covariates included are; Experience, experience squared and year dummies.

Table 10: Results from the three-period wage growth variance decomposition for different models.

\begin{tabular}{|c|c|c|c|c|c|c|c|}
\hline & \multicolumn{7}{|c|}{ Degree of contribution to the variance of three-period wage growth } \\
\hline & $(1)$ & $(2)$ & $(3)$ & $(4)$ & $(5)$ & (6) & $(7)$ \\
\hline$\theta$ & - & - & 0.1712 & 0.1742 & 0.1667 & 0.1868 & - \\
\hline$\psi$ & - & 0.0698 & 0.0765 & - & 0.0879 & - & 0.0774 \\
\hline$X \beta$ & 0.0397 & 0.0528 & 0.0407 & - & - & 0.0382 & - \\
\hline \multirow[t]{2}{*}{$\varepsilon$} & 0.9603 & 0.8774 & 0.7116 & 0.8258 & 0.7454 & 0.7750 & 0.9226 \\
\hline & \multicolumn{7}{|c|}{ Components included } \\
\hline$\theta$ & no & no & yes & yes & yes & yes & no \\
\hline$\psi$ & no & yes & yes & no & yes & no & yes \\
\hline$X \beta$ & yes & yes & yes & no & no & yes & no \\
\hline Observations & $17,680,262$ & $17,680,262$ & $17,680,262$ & $17,680,262$ & $17,680,262$ & $17,680,262$ & $17,680,262$ \\
\hline Workers & $1,724,736$ & $1,724,736$ & $1,724,736$ & $1,724,736$ & $1,724,736$ & $1,724,736$ & $1,724,736$ \\
\hline Firms & 254,920 & 254,920 & 254,920 & 254,920 & 254,920 & 254,920 & 254,920 \\
\hline Covariates & 3 & 3 & 3 & 0 & 0 & 3 & 0 \\
\hline
\end{tabular}

Note: Covariates included are; Experience, experience squared and year dummies. 
Figure 2: Degree of explanation given by worker effects, firm effects and covariates according to the variance decomposition plotted against number of person-years observed.

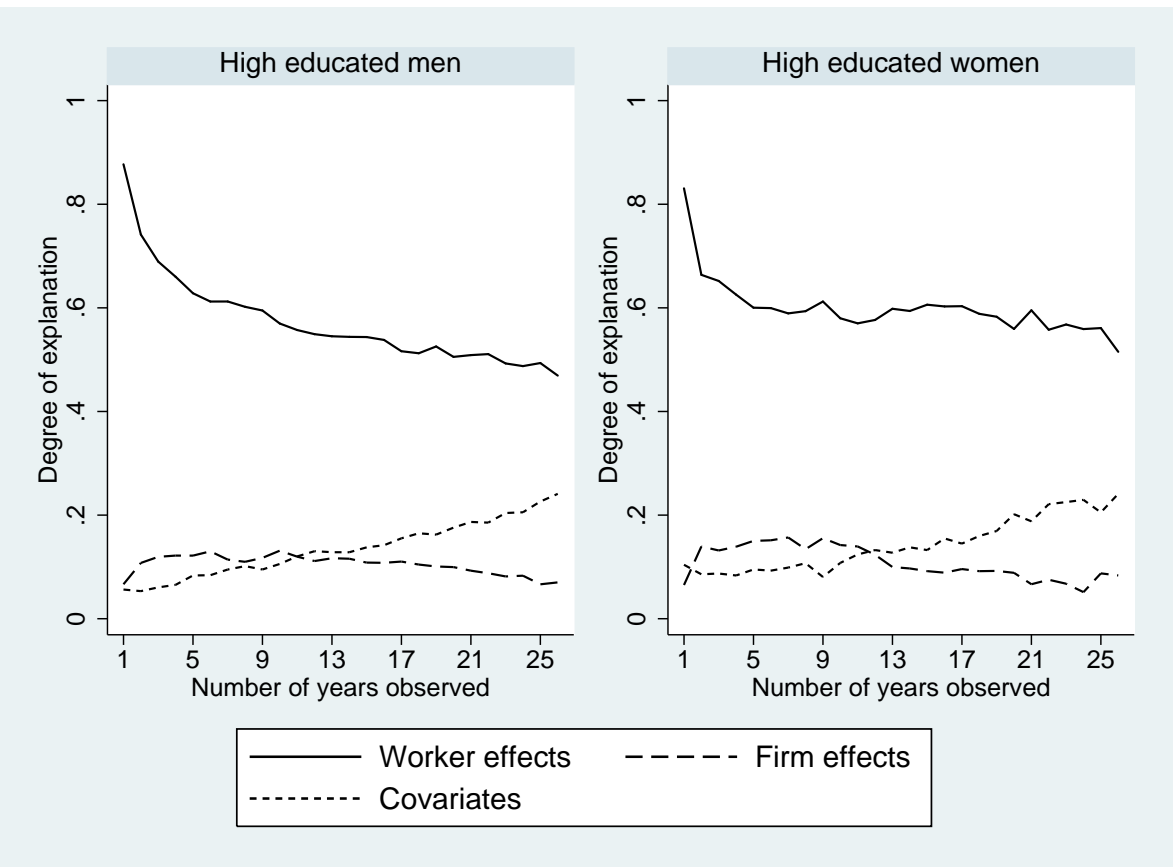

Figure 3: Degree of explanation given by worker effects, firm effects and covariates according to the variance decomposition plotted against number of person-years observed.

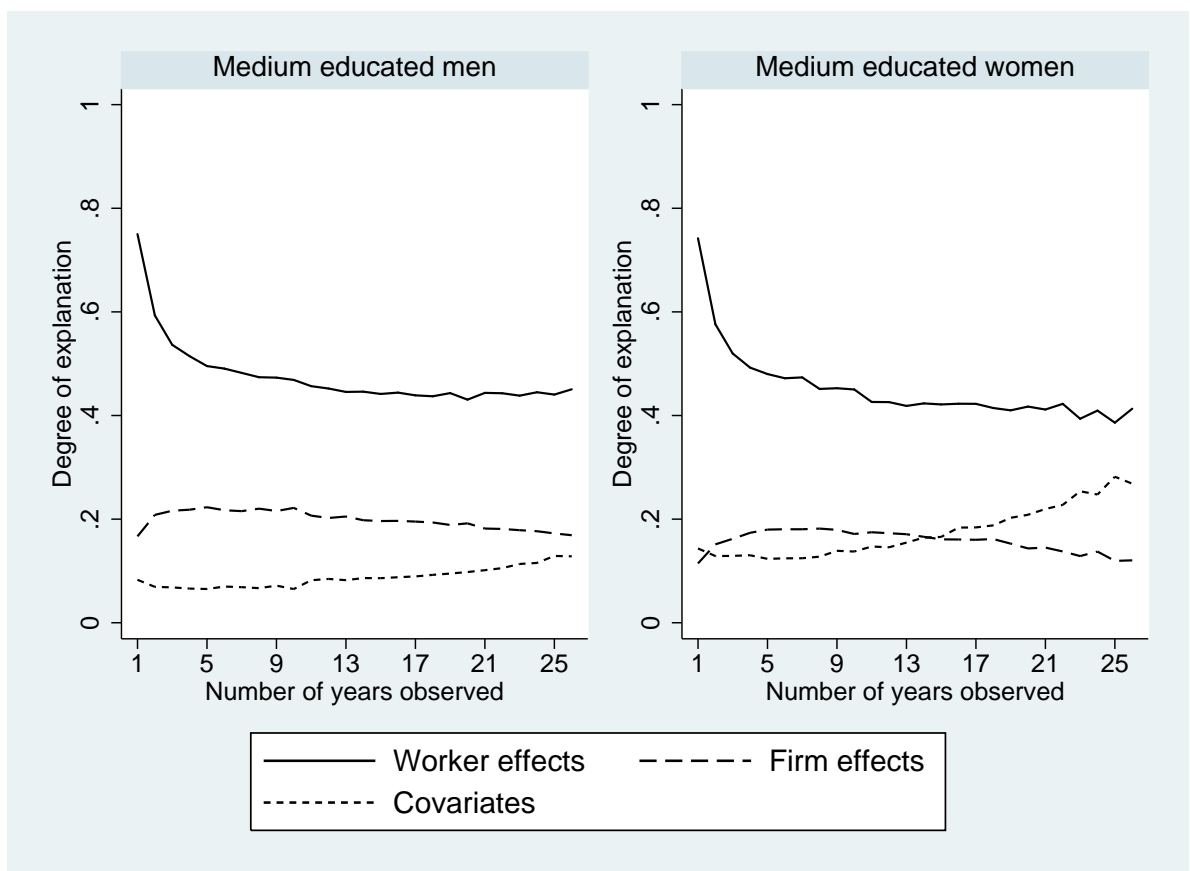


Figure 4: Degree of explanation given by worker effects, firm effects and covariates according to the variance decomposition plotted against number of person-years observed.

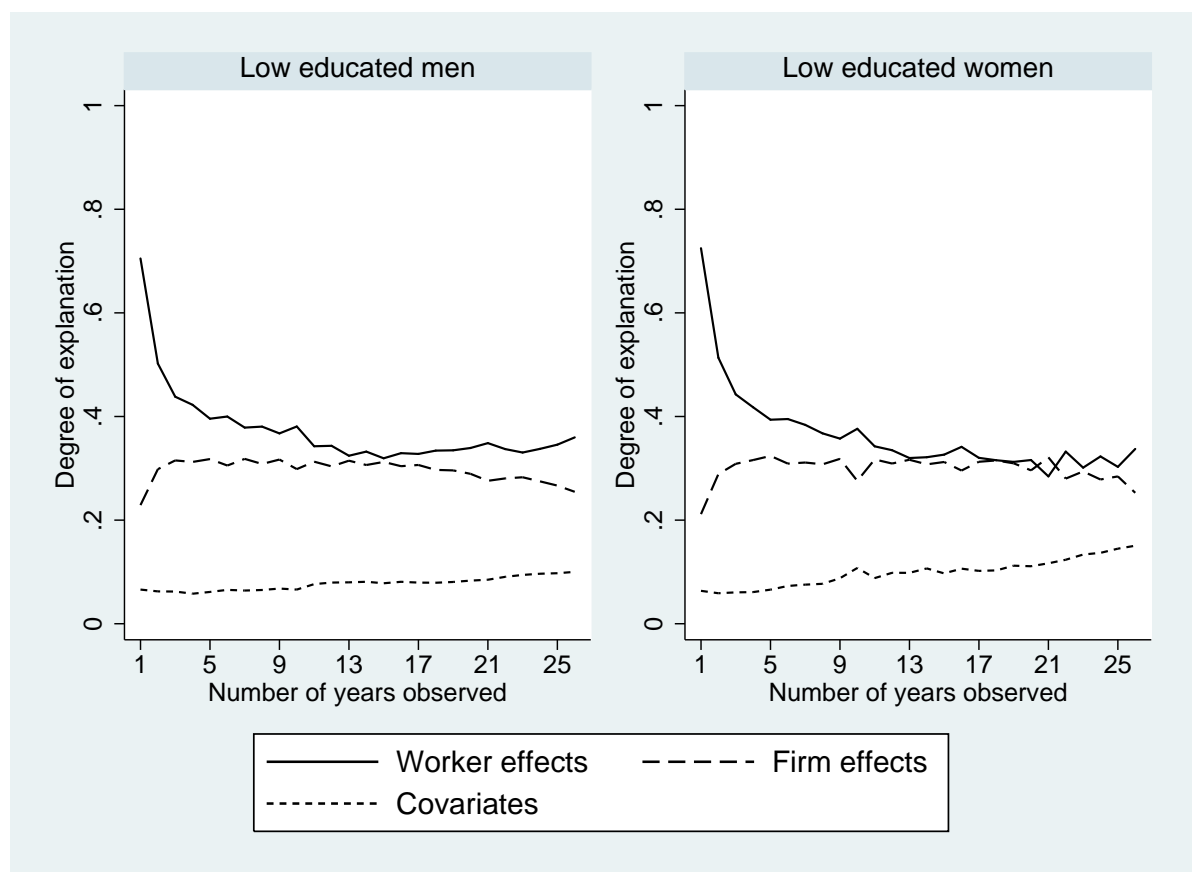




\section{Economics Working Paper}

2010-1: $\quad$ Laurent Callot and Martin Paldam: Natural funnel asymmetries. A simulation analysis of the three basic tools of meta analysis

2010-2: $\quad$ Allan Sørensen: Welfare Effects of Trade Liberalization with Intra-industry Reallocations: The Importance of Preferences and Market Failures

2010-3: $\quad$ Marianne Simonsen, Lars Skipper and Niels Skipper: Price Sensitivity of Demand for Prescription Drugs: Exploiting a Regression Kink Design

2010-4: $\quad$ Torben M. Andersen and Allan Sørensen: Product market integration, rents and wage inequality

2010-5: John Kennes and Daniel le Maire: Coordination Frictions and Job Heterogeneity: A Discrete Time Analysis

2010-6: $\quad$ Philipp J.H. Schröder and Allan Sørensen: The Theoretical Equivalent of Empirically Measurable Exporter Productivity when Firms are Heterogeneous

2010-7: $\quad$ Nabanita Datta Gupta and Marianne Simonsen: Effects of Universal Child Care Participation on Pre-teen Skills and Risky Behaviors

2010-8: $\quad$ Olaf Posch and Timo Trimborn: Numerical solution of continuous-time DSGE models under Poisson uncertainty

2010-9: Torben M. Andersen and Allan Sørensen: Globalization, tax distortions and public sector retrenchment

2010-10: $\quad$ Philipp J.H. Schröder and Allan Sørensen: Ad valorem versus unit taxes: Monopolistic competition, heterogeneous firms, and intra-industry reallocations

2010-11: Søren Leth-Petersen and Niels Skipper: Income and the use of prescription drugs for near retirement individuals

2010-12: $\quad$ Niels Skipper: On Utilization and Stockpiling of Prescription Drugs when Copayments Increase: Heterogeneity across Types of Drugs

2010-13: $\quad$ Kenneth L. Sørensen and Rune M. Vejlin: Worker and Firm Heterogeneity in Wage Growth: An AKM approach 